This is not the version of record. The full version of Van Elferen, Isabella (2020) Ludomusicology and the new drastic. Journal of Sound and Music in Games, 1(1), pp. 103-112 cam be found at https://doi.org/10.1525/jsmg.2020.1.1.103 


\title{
Ludomusicology and The New Drastic
}

\author{
Isabella van Elferen - Kingston University London
}

Video game music has begun to gain scholarly attention in the last fifteen years. Existing studies deal with topics including interactive technology and adaptive composition, ${ }^{1}$ game music's influence on player behaviour, ${ }^{2}$ and the similarities between game and film music. ${ }^{3}$ While these studies offer insights in single aspects of video game music, they also evoke the more fundamental question of game music's implications for musicology. This short contribution explores those implications. In a re-reading of Carolyn Abbate's seminal article 'MusicDrastic or Gnostic?' I will propose that the study of game music not only presents us with new research themes, but, moreover, that it has the potential to inspire a major disciplinary reform. The term 'ludomusicology' has come to refer to the investigation of music and play, especially, though not exclusively, through studying music in video games. ${ }^{4}$ Ludomusicology can lead to a New Drastic Musicology: an intellectual engagement with video game music that is just as rooted in immediacy, interactivity and playfulness as the object with which it concerns itself. The New Drastic, I shall argue, can engender significant critical, epistemological, thematic, and analytical innovations in the discipline of musicology. Fundamentally, my argument is that playing with music invites playing with critical music theory.

\section{Musicology - Gnostic vs. Drastic}

Carolyn Abbate's article 'Music - Drastic or Gnostic?' was published in 2004. In the article, she uses the concepts of drastic and gnostic to illustrate competing attitudes to understanding music. Abbate writes, 'The gnostic habit aims to expose something imperceptible to the untutored or uninitiated', 5 it 'implies not just knowledge per se but making the opaque transparent, knowledge based on semiosis and disclosed secrets, reserved for the elite and hidden from others' ${ }^{6}$ This has traditionally been the prevailing mode of musicological research.

\footnotetext{
${ }^{1}$ Karen Collins, Game Sound: An Introduction to the History, Theory and Practice of Video Game Music and Sound Design (Cambridge, MA: MIT Press, 2008); Elizabeth Medina-Gray, "Modular Structure and Function in Early 21st-Century Video Game Music" (PhD diss., Yale University, 2014); Winifred Phillips, A Composer's Guide to Game Music (Cambridge, MA: The MIT Press, 2014); Willem Strank, "The Legacy of iMuse: Interactive Music in the 1990s," in Music and Game: Perspectives on a Popular Alliance, ed. Peter Moormann (Wiesbaden: Springer VS, 2013), 81-92, and many others.

${ }^{2}$ William Cheng, Sound Play (New York: Oxford University Press, 2014); Laura Levy, Rob Solomon, Maribeth Gandy, and Richard Catrambone, “The Rhythm's Going to Get You: Music's Effects on Gameplay and Experience" (Proceedings of the 2015 Annual Symposium on Computer-Human Interaction in Play, New York, 2015), 607-612; Paul Toprac and Ahmed Abdel-Meguid, "Causing Fear, Suspense, and Anxiety Using Sound Design in Computer Games," in Game Sound Technology and Player Interaction: Concepts and Developments, ed. Mark Grimshaw (Hershey, PA: IGI Global, 2011), 176-191.

${ }^{3}$ Neil Lerner, "Mario’s Dynamic Leaps: Musical Innovations (and the Specter of Early Cinema) in Donkey Kong and Super Mario Bros.," in Music in Video Games: Studying Play, ed. K.J. Donnelly, William Gibbons and Neil Lerner (New York and London: Routledge, 2014), 1-29; Zach Whalen, "Case Study: Film Music vs. Video-Game Music: The Case of Silent Hill," in Music, Sound and Multimedia, ed. Jamie Sexton (Edinburgh: Edinburgh University Press, 2007), 68-81.

${ }^{4}$ For more on the term's origins, see Michiel Kamp, Tim Summers and Mark Sweeney, "Introduction," in Ludomusicology: Approaches to Video Game Music ed. Michiel Kamp, Tim Summers and Mark Sweeney (Sheffield: Equinox, 2016), 1-7.

${ }^{5}$ Carolyn Abbate, "Music - Drastic or Gnostic?," Critical Inquiry 30, no. 3 (2004): 505-536, at 528-529.

${ }^{6}$ Abbate, "Music - Drastic or Gnostic?," 510.
} 
In contrast, she characterizes much musical activity as having a 'drastic' quality, 'involving a category of knowledge that flows from [...] actions or experiences and not from verbally mediated reasoning. ${ }^{7}$ She suggests that little attention has been paid to music in its drastic sense, even though we frequently experience music in this way. We ignore important aspects of the musical experience if we do not recognize music's drastic qualities - that is, without understanding music as an event, in its performed incarnations, experienced as heard and played, rather than over-relying on the secondary, non-sounding materials (scores, recordings, etc.) that have typically been the domain of musicology.

Abbate calls for a musicology that researches the performative and immaterial aspects of playing and listening to music, next to the more traditional hermeneutics of musical scores and historical facts. Her argument built on the debates stirred by what was called the New Musicology' in the last decades of the $20^{\text {th }}$ century. That disciplinary movement emphasized the contextualization of music in terms of culture and society, and refocused attention away from 'great composers' who produced 'great works', and instead concentrated on the experience of listening to, interpreting, and performing, music. The influential author Christopher Small had argued that 'to music' should be a verb:

To music is to take part, in any capacity, in a musical performance, whether by performing, by listening, by rehearsing or practicing, by [composing], or by dancing. $[\ldots]$

The act of musicking [, Small argues,] establishes [...] a set of relationships, and it is in those relationships that the meaning of the act lies. They are to be found not only between those organized sounds which are conventionally thought of as being the stuff of musical meaning but also between the people who are taking part, in whatever capacity, in the performance. ${ }^{8}$

Nicholas Cook later engaged with the notions of musical performance and relationality in a 2001 article that emphasized music 'in/as performance', arguing that 'the musical work' is an event that should be researched in and through its - scripted and unscripted - performativity. ${ }^{9}$ Reasoning from there, he famously asserted later that 'we are all ethnomusicologists now'.10

In her assessment of musicology's possible 'new' routes, Abbate took a philosophical approach based on Vladimir Jankélévitch's work on musical performance. ${ }^{11}$ She radicalised the performative eventness of musicking to such an extent that she urged us as musicologists to transform our research methodologies and ask questions that explore the intangibility, ephemerality and - with Jankélévitch - even the ineffability of that musical event. Abbate opened a number of new philosophical avenues for musicology:

1. The critical engagement with music as an event, including immediacy, presence, liveness, and the possibility of non-temporality.

\footnotetext{
${ }^{7}$ Abbate, "Music - Drastic or Gnostic?," 510.

${ }^{8}$ Christopher Small, Musicking: The Meanings of Performance and Listening (Middletown: CT: Wesleyan University Press, 1998), 9; 13.

${ }^{9}$ Nicholas Cook, "Between Process and Product: Music and/as Performance," Music Theory Online 7, no. 2 (2001), www.mtosmt.org/issues/mto.01.7.2/mto.01.7.2.cook.html.

${ }^{10}$ Nicholas Cook, "We are All (Ethno)musicologists Now," in The New (Ethno)musicologies, ed. Henry Stobart (Lanham, MD: Scarecrow Press, 2008), 48-70.

${ }^{11}$ Vladimir Jankélévitch, Music and the Ineffable, trans. Carolyn Abbate (Princeton: Princeton University Press, 2003).
} 
2. The critical engagement with play: not just performance and performativity, but also the dialogic, the rapture, and the 'fun' of musicking ('doing this really fast is fun'), whether in performing music or listening to it.

3. The renewal of phenomenological debates about music, including questions of dis/embodiment, sensual perception, and the materiality of 'the musical work'.

Abbate's article was and still is controversial. Hermeneutic (interpretive) analysis does not necessarily create a static body of knowledge, nor is it concerned with composer biography, historical facts, and score analysis. Even if such research outcomes are generated, that information is typically couched in terms of its significance for changing performative and emergent meanings. However, the points Abbate made did resonate with a number of concerns in musicology, and have led to important new insights. In what follows I will explore the ways in which her approach can inform the study of video game music.

\section{The New Gnostic}

In terms of what Abbate calls 'the gnostic approach to music', game music can innovate existing hermeneutical traditions. Studies of game music composition take into account the fact that game audio needs to be adaptive in order to meet the unpredictable movements of players through the game; rather than on harmony and counterpoint, this research focuses on technological affordances and limitations, collaborations with game designers, and kinaesthetic design. ${ }^{12}$

Ludomusicology challenges the score analysis that musicologists have employed since the late nineteenth century. A combination of factors - the limited availability of game scores, the variation of musical output depending on player actions, the blurred boundaries between score and sound effects, and so on - often mean that traditional approaches to score-based analysis are often of limited use or relevance. Certainly games dispute the idea that treating music in terms of a fixed score should be the default mode of analysis. Games also invite other conceptions of scores, such as the graphical notations in music games like Guitar Hero, which provide instructions - or, as Cook would probably argue, 'scripts' - for play rather than precise notation. More often, the game itself becomes a graphical notation of the musicking event, as players journey through the virtual landscape, prompting musical events in the process of interacting with the game. Musical production, musical play, and musical interaction are thus much more intertwined and playful than in the traditional situation. Even under a 'gnostic' attitude to musical research, games present new materials and approaches, from radically different ways of conceiving of a musical score, to dealing with music programming systems, or the dynamics and contexts of game production.

\section{The New Drastic}

While the gnostic approach to game music can yield interesting results, the drastic approach is nowhere as appropriate and necessary as in the study of game music. Surprisingly, however, the genre is addressed neither by Abbate herself nor in the debates sparked by her article, and nor have game music studies taken on this approach. More than any other music, game music is an event, not a work; its performance is playful, immediate and interactive; its sound directly

\footnotetext{
${ }^{12}$ See, for example, Karen Collins, Playing with Sound: A Theory of Interacting with Sound and Music in Games (Cambridge, MA: MIT Press, 2013).
} 
influences the perception and phenomenology of the gaming experience. Game music, moreover, also urges questions that Abbate only hinted at: those pertaining to musical epistemology.

\section{Game Music as Event}

Game music is characterised by the same eventness as other types of musicking. Abbate argues that Wagner's Die Meistersinger should not be considered an abstract work, but 'a material, present event', ${ }^{13}$ that may engender all sorts of meaning while it lasts. In games that is perhaps even more true. Game music cannot be an abstract work whose genesis predates that of its actual performance, since its very presence depends on the way in which a player moves through the various stages of the game: players may linger in one game level, they may die several times, or they may move very fast, or even cheat and skip some stages. The performative shape of game music, its presence, is unpredictable, which arguably makes it more immediate and more 'live' even than Die Meistersinger could ever be. Playing games is making music.

While this principle of interactive eventness is operative in any video game, it becomes most evident in what are awkwardly called 'performance' music games such as Guitar Hero, Rock Band, and DJ Hero, and their mobile cousins such as Tap Sonic: games in which the player's goal is to produce sounding music by way of haptic interfaces - often in the shape of musical instruments such as guitars or drums. Ludomusicologists like Melanie Fritsch, Kiri Miller, and David Roesner have argued that these games do not only create immediacy, presence, and liveness, but also that playing these games engender a simultaneity of various kinds of performance: playing your plastic guitar is at once bringing forth the music, playing the game by pushing buttons, mimicking your favourite artist, and - if you are playing with friends - playing a performance for your social environment. ${ }^{14}$ Thus, the musical event created by these games is marked by a quadruple sense of performativity, presence, immediacy, and liveness.

\section{Game Musical Play}

Different types of musical play can be distinguished in video gaming. I have already discussed the actual playing of music in 'performance' music games. Because of the combination of gaming and musical interaction in this type of musical play there has been much popular and scholarly debate over the question to what extent games like Guitar Hero and Rock Band represent a 'real' musical activity. ${ }^{15}$ An argument often heard is that because players who are merely competent at video games can play it too, it therefore has nothing to do with music. Creating such a dichotomy between gaming and musicking is not very fruitful: what is interesting is precisely the fact that the two types of interactivity are blended together in game musical play.

Further types of musical play in games include playing with musical content in Brütal Legend, a game in which the player engages with the corpus of metal music as well as the subcultural capital pertaining to that genre; creating music in Wii Music, in which the player

\footnotetext{
${ }^{13}$ Abbate, "Music - Drastic or Gnostic?," 506.

${ }^{14}$ Melanie Fritsch and Stefan Strötgen, "Relatively Live: How to Identify Live Music Performances," Music and the Moving Image 5, no. 1 (2012): 47-66; Kiri Miller, Playing Along: Digital Games, YouTube, and Virtual Performance (New York: Oxford University Press, 2012); David Roesner, "The Guitar Hero's Performance," Contemporary Theatre Review 21, no. 3 (2011): 276-85.

${ }^{15}$ For example, see arguments reported in Dominic Arsenault, "Guitar Hero: "Not like playing guitar at all"?," Loading. . . 2, no. 2 (2008).
} 
can play an instrument 'by proxy' through the kinetic metaphor of game interface movement; and music-driven gameplay in games. Examples of the latter include games such as Patapon, a strategy game in which the player directs minions by playing particular rhythms on a set of drums (and which lend the game its title, e.g. 'pata-pata-pata-pon'). Recently a new type of musical play has emerged in games referred to as 'adaptive audio toys'. These games revolve around the gamer's playing around with her own musical instincts and memories, as the game mechanics consist of musical algorithms created by usually a touchscreen interface. In Remembering, for instance, players experiment with ambient soundscapes and graphics without having to achieve a gameplay goal. The designers of Remembering call this 'part experiment, part art project', which

tells a story through sound, music and abstract shapes. It is a slow, poetic journey about the beauty of conception and the trauma of being born. During this almost lucid dreamlike experience, you have limited control, and your gaze controls what you hear. [...] Remembering is about listening. By building a world based on sound instead of visuals we have created a place that relies on association rather than observation. ${ }^{16}$

These games all revolve around music in one way or another: but similar forms of play can be observed in non-music games too. Some video games feature diegetic music as a distinguishing part of gameplay. In the Grand Theft Auto games, for instance, players can choose from many radio stations to accompany their death drive; GTA $V$ features more than 130 stations of licensed 'real world' music. Choosing your station and setting your playlist is a form of playing music comparable to Rock Band. It also involves playing with musical content and subcultural connotations like in Brütal Legend and a form of musical memory play comparable to Remembering (only slightly less zen). Similarly, but possibly even more interesting, is nondiegetic game audio. The music for the Assassin's Creed games, for example, received great popular as well as critical acclaim. This music not only creates the right mood for the game by way of musical connotations and memories, just like in Brütal Legend, it also guides you through gameplay by way of musical navigation clues such as leitmotivs, stingers, and stereo effects, just like the more explicit 'pata-pata-pata-pons' do; and in this sense the music plays you as much as you play it, just like in Remembering.

Playing with music also takes the shape of extended play. On online platforms like Remixsquared, Overclocked remix, and ThaSauce, game music fans create new music with the musical materials provided by games in an astounding number of remixes. Other fans play around with game hardware. Some musicians and DJs involve hardware such as the Nintendo Game Boy or the Commodore 64 in their live performances; others try their hand at chiptunes, a composing style with game soundchip technology that has become so popular that it is now a very active subculture on its own. With chiptunes, 'playing with game music' extends not only outside the actual game, but also outside the time in which that game was made. Moreover, the playfulness of chiptunes involves non-gaming musicality as well, as many artists remake existing songs. This in turn engenders a complex play with musically invoked identification strategies. The chiptune remix of A-Ha's 'Take On Me', for instance, evokes my personal 1980s identity as well as old-fashioned gaming memories and contemporary mashup culture. Extended game musical play, thus, can also be understood as a play with identification.

Such ludo-musical practices urge musicologists to refine their understanding of musical play and performance, raising questions such as: In which ways does ludo-musicking challenge existing theories of musical performance? How can the musical play characterising game

16 Quotations from the website and presskit for Remembering. Monobanda. 2017. http://www.rememberingthegame.com/remembering-home (accessed July 20, 2019). 
composing be likened to that in music-historical situations? Important steps in this latter direction have been taken by Roger Moseley, who analyses playful musical cultures from Mozart to Nintendo in his book Keys to Play. ${ }^{17}$

Karen Collins starts and ends her latest book on game music with the assertion that 'interacting with sound is fundamentally different from listening to sound'. ${ }^{18}$ While that seems logical at face value, the examples I have just presented rather suggest that the lines between playing and listening are not as clear-cut as that. Such findings are confirmed by the phenomenological research of Don Ihde and Jean-Luc Nancy, who have both argued that listening is interactive, performative, and of great influence to subject formation. ${ }^{19}$ Thus, considerations of game musical play lead to questions pertaining to the phenomenology of game music.

\section{Game Music Phenomenology}

Timothy Crick has argued that video gaming phenomenology is threefold: 'the player is effectively in control of three bodies: the avatar's body, his or her own body, and visual perspective of a "game body". ${ }^{20}$ The phenomenology of game music enhances this doubling or tripling effect. Kiri Miller states that players of Guitar Hero are 'playing between

- that is, playing in the gap between virtual and actual performance'. ${ }^{21}$ This liminal phenomenology of game musical play is enhanced by the phenomenology of listening: listening itself always engenders a private virtual space that consists solely of music and its multivalent connotations. So players participate in the game diegesis, as well as in extra-diegesis, while creating music that is supra-diegetic. Through this process you find yourself in the real world, in the virtual world, in augmented reality, and in all of these at once. This situation does not only hold true for playing Rock Band, but, as we have seen, also for Patapon, Brütal Legend, GTA, Remembering, and Assassin's Creed. Whether one is playing music, playing with music, creating music or extended musical play: all of this must be considered ludomusicking, a concept which needs closer phenomenological scrutiny and refinement.

One interesting avenue of research would have to be the introduction of the notion of inattentive performance, which would combine Anahid Kassabian's thinking around inattentive listening with Abbate's ideas concerning the musician's self-forgetfulness: the seemingly timeless 'fun' of playing music. ${ }^{22}$ In music games like Rock Band, Wii Music, and Remembering, the player does not only play the music, but also the game, as well as enact their own musical memory. This multi-layered form of musicking intensifies the thoughtless immediacy of traditional musical performance. Music for games like Assassin's Creed is often composed as non-diegetic, unconsciously perceived music geared towards inattentive listening: since playing a game is performing its music this, too, is a form of inattentive performance. Games in which music is neither diegetic nor non-diegetic (or both) - Patapon, Brütal Legend, and Grand Theft Auto - are similarly characterised by inattentive performance.

\footnotetext{
${ }^{17}$ Roger Moseley, Keys to Play (Berkeley: University of California Press, 2016).

${ }^{18}$ Collins, Playing With Sound, 2, 7, 143.

${ }^{19}$ Don Ihde, Listening and Voice, $2^{\text {nd }}$ ed. (Albany: State University of New York Press, 2007); Jean-Luc Nancy, Listening, trans. Charlotte Mandell (New York: Fordham University Press, 2007).

${ }^{20}$ Timothy Crick, "The Game Body: Toward a Phenomenology of Contemporary Video Gaming," Games and Culture 6, no. 3 (2011): 259-269, at 262.

${ }^{21}$ Miller, Playing Along, 16.

${ }^{22}$ Anahid Kassabian, Ubiquitous Listening: Affect, Attention, and Distributed Subjectivity (Berkeley: University of California Press, 2013); Abbate, "Music - Drastic or Gnostic?," 511.
} 
Following Jankélévitch, Abbate has drawn attention to musicking subjectivity, positioned as it is between embodied performance and mental, emotional, or even spiritual appreciation. Ludomusicology provides an exciting opportunity to revisit the phenomenology of music and listening, as it offers critical assessments of the gap between virtual and actual musicking, as well as their ambivalent embodiments.

\section{Game Musical Epistemology}

Finally, the questions evoked by game musical eventness, play, and phenomenology urge a music philosophical question that has remained unresolved from Pythagoras to John Cage. In which ways can we 'think music'? As acoustic vibrations generated by instruments and voices, sound and music can be theorized through ontological materialism; ${ }^{23}$ but as performative events leading to aesthetic and affective experiences, sound and music must be thought in the realm of phenomenology, which has a much less comfortable relation to materialism. ${ }^{24}$ Because of its uneasy fit between ontology and phenomenology, between materiality and immateriality, musical epistemology is haunted by the paradoxical materialism of its own subject matter.

Ludomusicology can lead to a major shift in the epistemology of music. The eventness and interactivity of game music change notions of music's emergent meanings; play and performance problematise subjectivity; and any attempt at a phenomenology of game music inevitably leads to the question of music's ontology.

In order to understand precisely how ludomusicology can contribute to musical epistemology I would like to return to Christopher Small, who argues that

Musicking is about relationships, not so much about those which actually exist in our lives as about those that we desire to exist and long to experience: relationships among people, as well as those between people and the rest of the cosmos, and also perhaps with ourselves and with our bodies and even with the supernatural [...]. During a musical performance [...] desired relationships are brought into virtual existence so that those taking part are enabled to experience them as if they really did exist. ${ }^{25}$

Small, thus, asserts that musicking can evoke the ineffable, a concept referred to explicitly by Abbate (echoing Jankélévitch) - something that is vague, intangible, rather slippery and empathically non-intellectual. Precisely the ineffable, however, is key for our understanding of musical performativity and relationality. In his assessment of musical authenticity, Peter Kivy writes about a gap between musical phenomenology and musical ontology that produces the ineffable:

The 'logic' of music as a performing art [...] is a logic in which the gap between 'text' and performance is not merely a necessary evil but at the same time a desired, intended and logically required ontological fact. It is in that gap that the work of art is produced that we call 'performance' $\left[\ldots . .{ }^{26}\right.$

\footnotetext{
${ }^{23}$ Carl Matheson and Ben Caplan, "Ontology," in The Routledge Companion to Philosophy and Music, ed. Theodore Gracyk and Andrew Kania (New York: Routledge, 2011), 38-47.

${ }^{24}$ Bruce Ellis Benson, "Phenomenology of Music," in The Routledge Companion to Philosophy and Music, ed. Theodore Gracyk and Andrew Kania (New York: Routledge, 2011), 581-591.

${ }^{25}$ Small, Musicking, 183.

${ }^{26}$ Peter Kivy, Authenticities: Philosophical Reflections on Musical Performance (Ithaca: Cornell University Press, 1995), 272.
} 
Kivy is talking here about historical performance practice, but his observations have much wider implications. It is this gap, this aperture onto the ineffable, that I want to get at, and I believe that the gap is brought to the foreground by game music. Ludomusicology can intervene in the gap between text and performance, and in the gap between real-life embodiment and virtual disembodiment: this is the gap between virtual and actual performance mentioned by Miller. Ludomusicology inhabits the gap between musical phenomenology and musical ontology: Small mentioned the 'virtual existence' within that gap; it challenges musical epistemology; and therefore it can arrive at a conceptualisation of the musical ineffable. The study of game music is able to continue, reformulate, and develop Abbate's ideas about gnostic and drastic musicology: therefore ludomusicology is a new form of drastic musicology.

\section{Conclusion}

Game music not only transforms musical practice but also challenges musicological praxis. Innovating the discipline on the gnostic levels of object analysis, and inviting disciplinary reflections on musical eventness, performance, phenomenology and epistemology, a true ludomusicology, that is, a playing with musical critical theory as well as with music, can and should engender 'The New Drastic'.

\section{Bibliography}

Abbate, Carolyn. "Music - Drastic or Gnostic?." Critical Inquiry 30, no. 3 (2004): 505-536.

Arsenault, Dominic. “Guitar Hero: "Not like playing guitar at all”?.” Loading. . . 2, no. 2 (2008).

Benson, Bruce Ellis. "Phenomenology of Music." In The Routledge Companion to Philosophy and Music, edited by Theodore Gracyk and Andrew Kania, 581-591. New York: Routledge, 2011.

Cheng, William. Sound Play. New York: Oxford University Press, 2014.

Collins, Karen. Game Sound: An Introduction to the History, Theory, and Practice of Video Game Music and Sound Design. Cambridge, MA: The MIT Press, 2008.

Collins, Karen. Playing with Sound: A Theory of Interacting with Sound and Music in Games. Cambridge, MA: MIT Press, 2013.

Cook, Nicholas. "Between Process and Product: Music and/as Performance." Music Theory Online 7, no. 2 (2001), www.mtosmt.org/issues/mto.01.7.2/mto.01.7.2.cook.html.

Cook, Nicholas. "We are All (Ethno)musicologists Now." In The New (Ethno)musicologies, edited by Henry Stobart, 48-70. Lanham, MD: Scarecrow Press, 2008.

Crick, Timothy. "The Game Body: Toward a Phenomenology of Contemporary Video Gaming." Games and Culture 6, no. 3 (2011): 259-269.

Fritsch, Melanie, and Stefan Strötgen. "Relatively Live: How to Identify Live Music Performances." Music and the Moving Image 5, no. 1 (2012): 47-66.

Ihde, Don. Listening and Voice. 2nd ed. Albany: State University of New York Press, 2007.

Jankélévitch, Vladimir. Music and the Ineffable. Translated by Carolyn Abbate. Princeton: Princeton University Press, 2003. 
Kamp, Michiel, Tim Summers and Mark Sweeney. "Introduction." In Ludomusicology: Approaches to Video Game Music edited by Michiel Kamp, Tim Summers and Mark Sweeney, 1-7. Sheffield: Equinox, 2016.

Kassabian, Anahid. Ubiquitous Listening: Affect, Attention, and Distributed Subjectivity Berkeley: University of California Press, 2013.

Kivy, Peter. Authenticities: Philosophical Reflections on Musical Performance. Ithaca: Cornell University Press, 1995.

Lerner, Neil. "Mario's Dynamic Leaps: Musical Innovations (and the Specter of Early Cinema) in Donkey Kong and Super Mario Bros." In Music in Video Games: Studying Play, edited by K.J. Donnelly, William Gibbons and Neil Lerner, 1-29. New York and London: Routledge, 2014.

Levy, Laura, Rob Solomon, Maribeth Gandy, and Richard Catrambone. "The Rhythm's Going to Get You: Music's Effects on Gameplay and Experience." Proceedings of the 2015 Annual Symposium on Computer-Human Interaction in Play, 607-612. New York, 2015.

Matheson, Carl, and Ben Caplan. "Ontology.” In The Routledge Companion to Philosophy and Music, edited by Theodore Gracyk and Andrew Kania, 38-47. New York: Routledge, 2011.

Medina-Gray, Elizabeth. "Modular Structure and Function in Early 21st-Century Video Game Music." PhD diss., Yale University, 2014.

Miller, Kiri. Playing Along: Digital Games, YouTube, and Virtual Performance. New York: Oxford University Press, 2012.

Moseley, Roger. Keys to Play. Berkeley: University of California Press, 2016.

Nancy, Jean-Luc. Listening. Translated by Charlotte Mandell. New York: Fordham University Press, 2007.

Phillips, Winifred. A Composer's Guide to Game Music. Cambridge, MA: The MIT Press, 2014.

Remembering. Monobanda. 2017. http://www.rememberingthegame.com/remembering-home (accessed July 20, 2019).

Roesner, David. “The Guitar Hero's Performance." Contemporary Theatre Review 21, no. 3 (2011): 276-85.

Small, Christopher. Musicking: The Meanings of Performance and Listening. Middletown: CT: Wesleyan University Press, 1998.

Strank, Willem. "The Legacy of iMuse: Interactive Music in the 1990s." In Music and Game: Perspectives on a Popular Alliance, edited by Peter Moormann, 81-92. Wiesbaden: Springer VS, 2013.

Toprac Paul, and Ahmed Abdel-Meguid. "Causing Fear, Suspense, and Anxiety Using Sound Design in Computer Games." In Game Sound Technology and Player Interaction: Concepts and Developments, edited by Mark Grimshaw, 176-191. Hershey, PA: IGI Global, 2011.

Whalen, Zach. "Case Study: Film Music vs. Video-Game Music: The Case of Silent Hill." In Music, Sound and Multimedia, edited by Jamie Sexton, 68-81. Edinburgh: Edinburgh University Press, 2007. 
Accepted manuscript for Journal of Sound and Music in Games 2019. Do not quote until published. 